\title{
FIGHTING BEHAVIOR OF \\ MALE GOLOFA PORTERI BEETLES \\ (SCARABEIDAE: DYNASTINAE)*
}

BY WiLliam G. EBERHARD

Depto. de Biología

Universidad del Valle

Cali, Colombia, and

Smithsonian Tropical Research Institute

P. O. Box 2072

Balboa, Canal Zone

Large males of Golofa porteri possess several striking secondary sexual characteristics: the head has a long, curving horn with serrations along its edges; the prothorax has an even longer, thinner, nearly vertical horn which is smooth and covered on its anterior surface with a thick mat of golden hairs; and the front legs, especially the robust tibiae and tarsi, are monstrously elongate, with the last tarsomeres sporting thick growths of golden hair on their ventral surfaces.

Howden and Campbell (1974) observed two struggles between males in nature at apparent feeding sites on long thin stalks of a bamboo-like plant. Wille (1943) also noted G. aegeon (especially males) on sugar cane stalks. This study is a follow-up of these observations to determine the functions of the males' bizarre secondary sexual structures.

\section{METHODS}

Males were captured near lights at night and kept individually in metal canisters where they were provided with pieces of ripe banana or plantain which they appeared to eat. Fights were staged in the evening on nearly vertical, $1.5-2.5 \mathrm{~cm}$ diameter stalks (mostly the central rachi of palm leaves from which I had stripped the leaflets). The first male was placed on the stalk facing down, and within 1-5 min. the second was added below him, facing up. Super- 8 movies made of eight fighting sequences and associated behavior were analyzed frame by frame. Substantial enlightenment was also

* Manuscript received by the editor March 26, 1978. 
gained using the old technique, employed by Joseph (1928) in his study of Chiasognathus grandti, of watching partially senile males whose movements were slowed. Male G. porteri were extraordinarily pugnacious, and even attacked fingers poked at them (especially when the finger made contact with the base of the prothoracic horn). When in good condition, they fought readily.

\section{RESULTS}

\section{A. Physical combat}

Howden and Campbell (1974) described one fight they saw: "They grappled with their elongated forelegs, as each attempted to place the head horn under the opponent ... suddenly the larger male successfully placed his head horn under his opponent and flipped him off the stalk." They were correct in attributing a leverlike use to the head horn, but the "grappling" with the forelegs turns out to be more complex and functionally interesting than suspected.

In outline, a beetle attacking a non-responsive opponent typically behaves in the following way. Before sensing the other, he uses his middle and hind legs to hold tightly to the stalk, leaving his front legs essentially inactive. Upon sensing the opponent's presence (in some cases apparently at long range, in others not until contact was made), he lowers his head horn so it is nearly but not quite parallel to the stalk. At the same time he spreads his front legs so as to nearly or completely encircle the stalk at about the level of his head (Fig. 1a). Particularly aggressive males assume this position with such a snap that the stalk quivers, and, as indicated in Fig. 1a, sometimes abruptly raise and lower the legs in an apparent threat. The male then attempts to insert his head horn under the opponent by raising his prothorax away from the stalk and lowering his head still more. Easing forward and/or pulling his opponent toward him with his front legs, he positions the end of the horn far back under the opponent's body. As he does so, he brings his long front legs along the opponent's sides (Fig. 1b). Finally he attempts to pry him loose with a double attack. The front legs are raked postero-ventrally, dislodging the opponent's middle and/or hind legs which grip the stalk, and an instant (about $1 / 30 \mathrm{sec}$.) later, the head is savagely flexed dorsally to lift him (Fig. 1c). The result of a successful attack is to break 

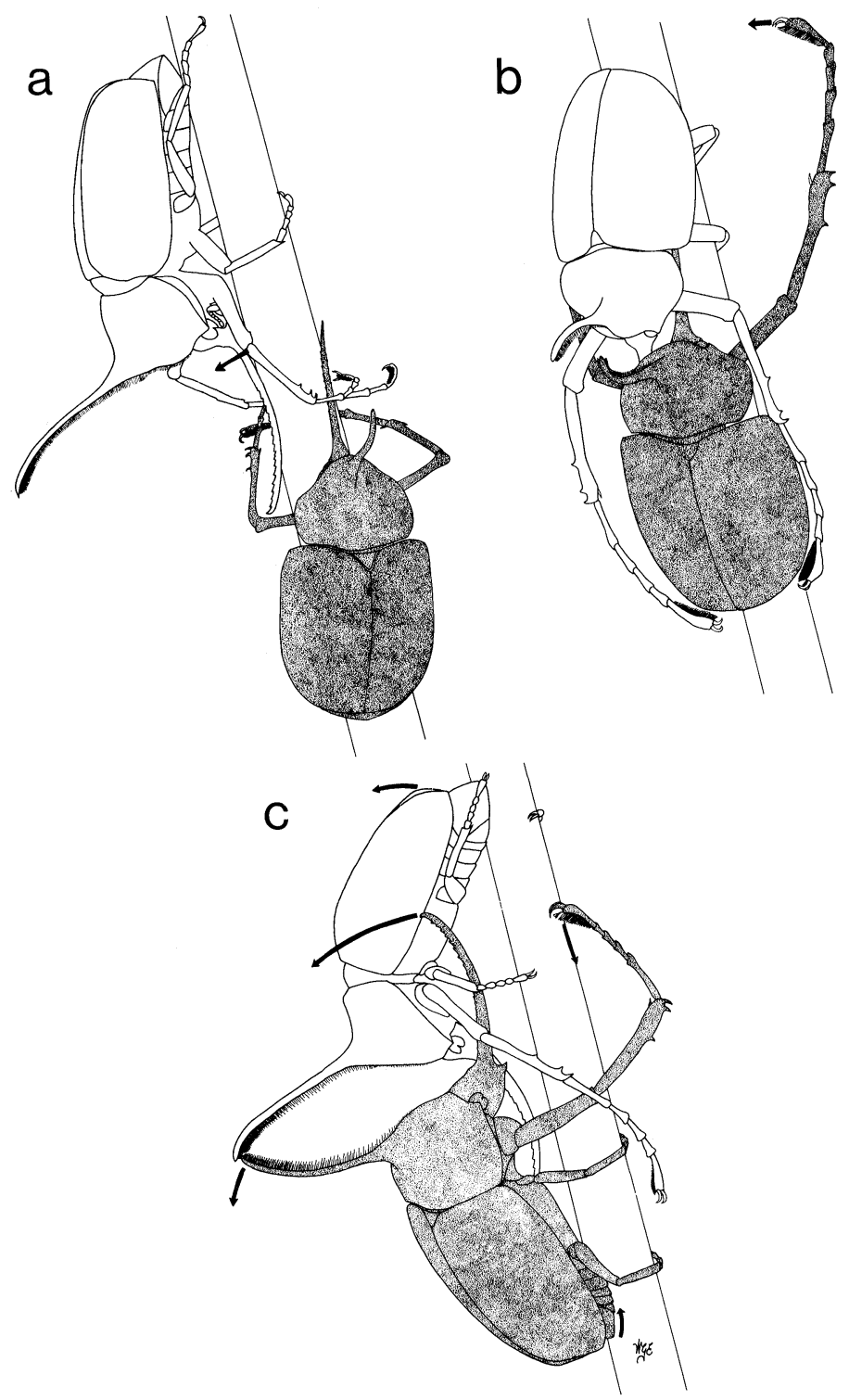
the opponent's grip on the stalk and then pry him away from it, hold him briefly between the winner's head and prothoracic horn, and drop him. In some cases neither beetle was lifted completely free, but there was a clear winner, and the loser turned and walked away.

In most battles, of course, the chain of events was not this simple because each beetle resisted the other's attempts to dislodge him, and the result was often a confusing tangle of legs and horns. Periodic violent thrusting and lifting motions of the head horns occurred, sometimes accompanied by ripping motions of the front legs and sometimes not; of fifteen clear thrusts in filmed sequences, seven were immediately preceded by a ripping movement, five were probably preceded by ripping, two were not preceded by ripping, and one was unclear. Occasionally a beetle raised his front legs suddenly during the grappling between thrusts, and then held them in the circle position adopted at the start of encounters (Fig. 1a). This movement could conceiveably serve as a defense against encirclement by the opponent's front legs, and in this case the large lateral tibial spines might serve to catch his legs. The leg interchanges between beetles were so variable, however, that it was not possible to be certain of these functions.

Figure 1. Stages in a struggle between two male G. porteri, drawn from frames of movie film taken at $30 \mathrm{fps}$ (arrows indicate movement by showing positions of legs, etc. in the next frame). a) The upper male has encircled the stalk with his front legs. In the next frame he made an apparent threat by abruptly raising his legs slightly, and then (in the following frame) lowering them again. b) Each beetle has inserted his lowered head horn under the opponent, and, while holding the stalk tightly with his middle and hind legs, is "embracing" the opponent with his front legs (note how the elongate legs just fit the length of the other beetle's body). c) The lower beetle has just executed the ripping motion with his front legs, dislodging his opponent's left middle and hind legs, and is about to (next frame) flex his head dorsally to pry the opponent away from the stalk. His head horn was not under the central part of the upper beetle's body but was somewhat to the right (as seen in the drawing), and the attack was not successful since the opponent managed to keep his right rear foot hooked to the stalk. (The upper beetle's left middle and left rear legs were out of the focal plane, and their positions are estimated in the drawing from shadows cast on the stalk and from other lifting sequences. The lower beetle's head horn was not distinguishable in the next frame, presumably because it was moving so fast, but was clear (the head flexion had finished) in the following frame; its movement (arrow) was estimated by halving the distance between its position prior to and after the flexion.) 
B. Stridulation and substrate vibration

Physical combat was always associated with other behavior whose probable function was intimidation. As also noted by Howden and Campbell (1974), beetles produced soft "squeaking" or "chirping" sounds. These were made before, during, and after battles, and were the result of scraping a file running longitudinally on the dorsum of the tip of the abdomen back and forth against the tips of the elytra. The number of chirps varied from two (one downward and one upward stroke) to more than 20; chirps were made as fast as about 12 strokes/sec. Beetles being teased with a finger gave a single pair of chirps accompanying each thrust with the head horn.

Males also sometimes shook the entire stalk by vibrating the body rapidly from side to side (about 10 cycles/sec) while resting in one place. This behavior was usually performed by a winning beetle just after a battle, and was accompanied by simultaneous stridulation.

\section{Climbing and flying behavior}

The males' long front legs were not the encumbrance to walking along the stalk that might be expected. They were held bent ventrally so that the two tibiae touched each other, or nearly so, on the other side of the stalk, and were used in a manner similar to that of telephone linemen using belts as they climb poles. Beetles climbing upward moved each pair of legs simultaneously, the order being middle, hind, and, just slightly later, front. Descending beetles moved their legs in a similar manner, with the added variation that the strong spurs on the inner margins near the tips of the tibiae were apparently used as spikes to engage the stalk.

Beetles sometimes decamped after fights by climbing to the upper tip of the stalk and flying away. They flew strongly, and could hover more or less stationary for seconds at a time. They held their front legs folded with their tarsi projecting forward and upward, so that they reminded one, with these paired, hook-shaped structures, of a bat hanging by its hind legs.

\section{DISCUSSION}

There seems little doubt, from the combination of observations of fights in nature and in captivity, that the horns and elongate front legs of $G$. porteri males function in fights between conspe- 
cifics. This species is thus in accord with the tendency seen in other beetles for such male structures to function as weapons in intraspecific battles (Eberhard in press). It differs from the others investigated so far in that the legs and horns (at least the prothoracic horn) may have the additional function of intimidating opponents with prefight visual displays; the fights occur at least sometimes during the day in the open, and the jerking movements of the front legs may serve to focus attention on them.

The elongate front legs constitute the most unusual feature of this species, and it is possible to speculate on possible evolutionary sequences for their development. Head horns, functioning to pry up adversaries in what seems to be the usual beetle manner (see Eberhard in press) probably evolved first. The effective use of the head horn probably involved pushing ventrally with the front legs at the moment of dorsal flexion of the head to impart maximum dorsal thrust; it may have also involved clamping the opponent against a thoracic horn and lifting him away from the substrate. Two possible sequences leading to long legs occur to me. 1) Preliminary lengthening of the front legs might have been advantageous to permit the beetle to apply the downward thrust of the legs farther forward, thus giving greater mechanical advantage to the head's upward thrust since the lift would be exerted nearer the beetle's center of gravity. Both head horn and front legs might have then increased in parallel fashion since better purchase would increase the effectiveness of a longer horn as a pry. The next stage would begin when the front legs were long enough that they reached the opponent's middle legs and occasionally dislodged one accidentally as they pushed down during a thrust. Natural selection could then favor further elongation of the legs, perfection of the timing and form of the ripping movement, and concomitant loss of the bracing function during head thrusts until the present state was achieved. 2) Lengthening of the front legs might have begun as an adaptation to raise the opponent farther from the substrate after he had been clamped between the head and prothoracic horns. Raising him farther would be advantageous because he would be more likely to lose his contact with the substrate, and would thus be more likely to fall free when dropped. Selection of this sort may have occurred in other beetles like Chiasognathus grandti, which have moderately long front legs and which lift opponents in fights in the open (Joseph 1928). When these long legs 
also began to accidentally dislodge legs of opponents, they could have evolved as described above to the present state, again losing their original function in the process. A combination of sequences 1 and 2 could also have occurred.

\section{SUMMARY}

The horns and long front legs of male Golofa porteri function as effective weapons in intraspecific battles between males.

\section{ACKNOWLEDGEMENTS}

I am indebted to Sr. Jorge Garavito of Telecom, Colombia for providing me with a crucial batch of beetles, and I thank Drs. M. J. W. Eberhard and H. Howden for criticizing the manuscript. This work was supported financially by the Comite de Investigaciones, Universidad del Valle.

\section{Literature Cited}

EBERHARD, W. G.

In press. The function of horns in the dynastine Podischnus agenor and other beetles. In: M. Blum and A. Blum (ed.) Sexual Selection and Reproductive Competition in Insects. Academic Press, New York.

Howden, H., AND M. CAMPBell

1974. Observations on some scarabaeoidea in the Colombian Sierra Nevada de Santa Marta. Coleop. Bull. 28(3): 109-114.

JOSEPH, C.

1928. El Chiasognathus Grandti Steph. Rev. Universitaria (U. Católica) (Santiago, Chile). 13(1): 529-535.

Wille, J. E.

1943. Entomología Agrícola del Peru. Ministerio de Agricultura, Lima. 

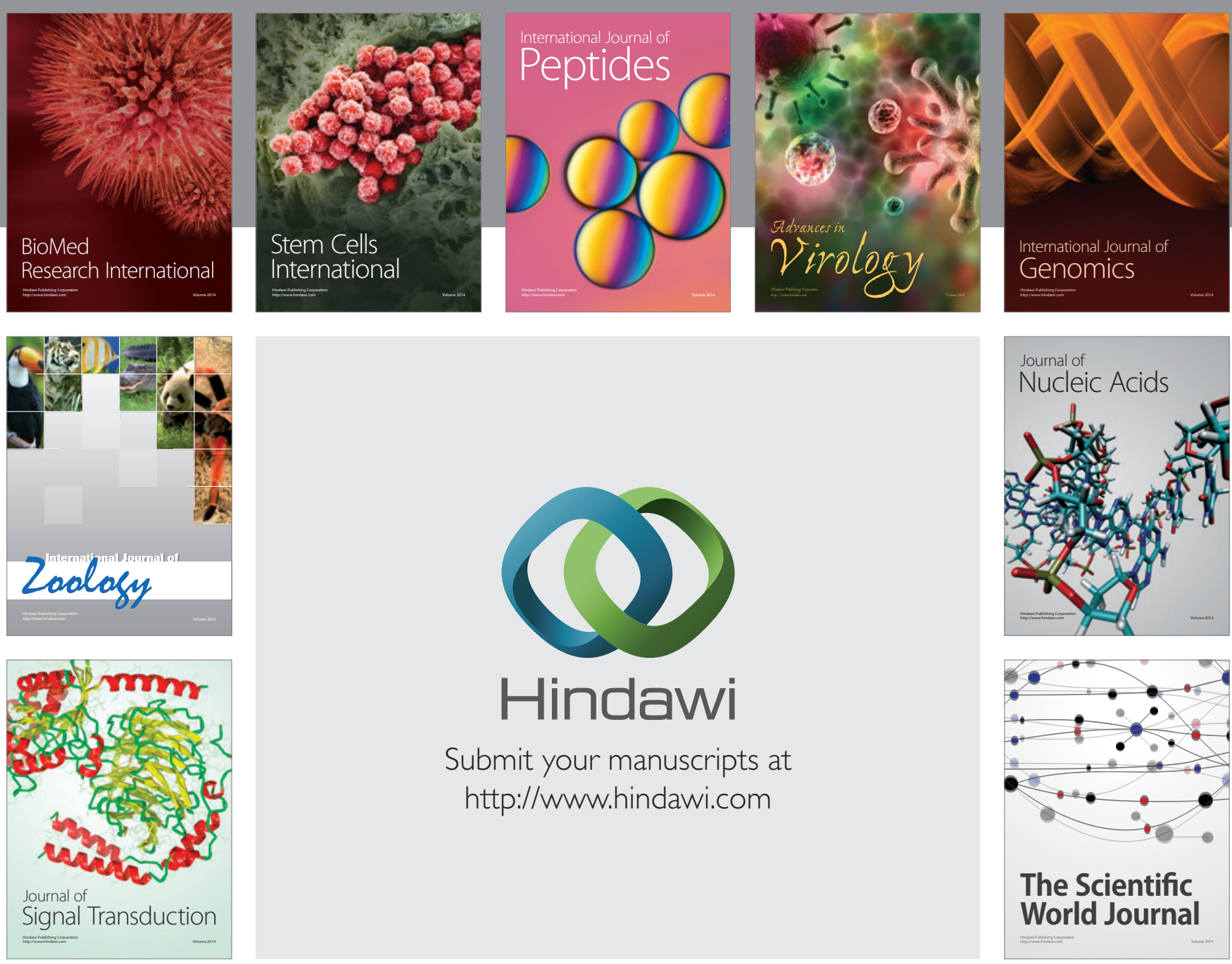

Submit your manuscripts at

http://www.hindawi.com
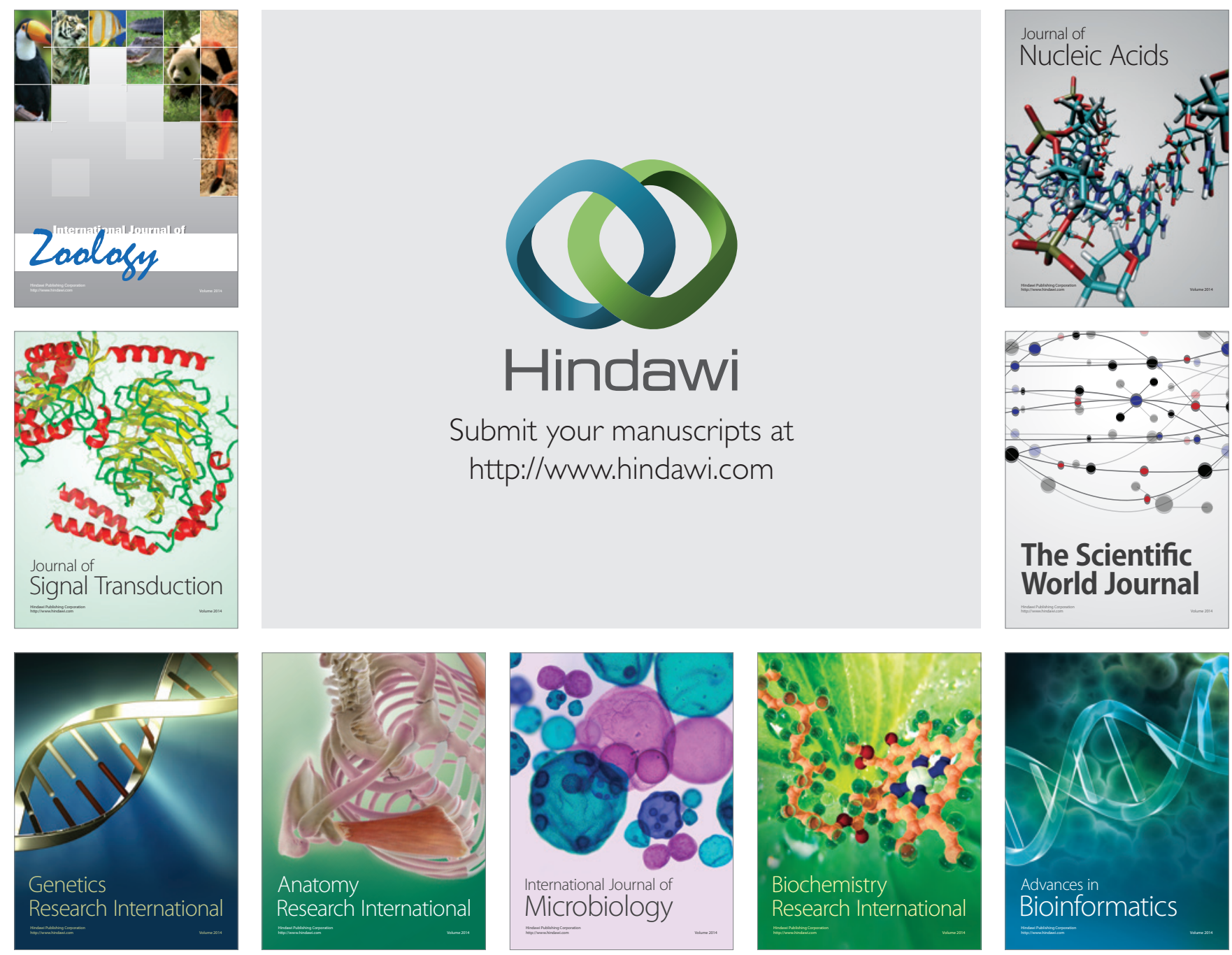

The Scientific World Journal
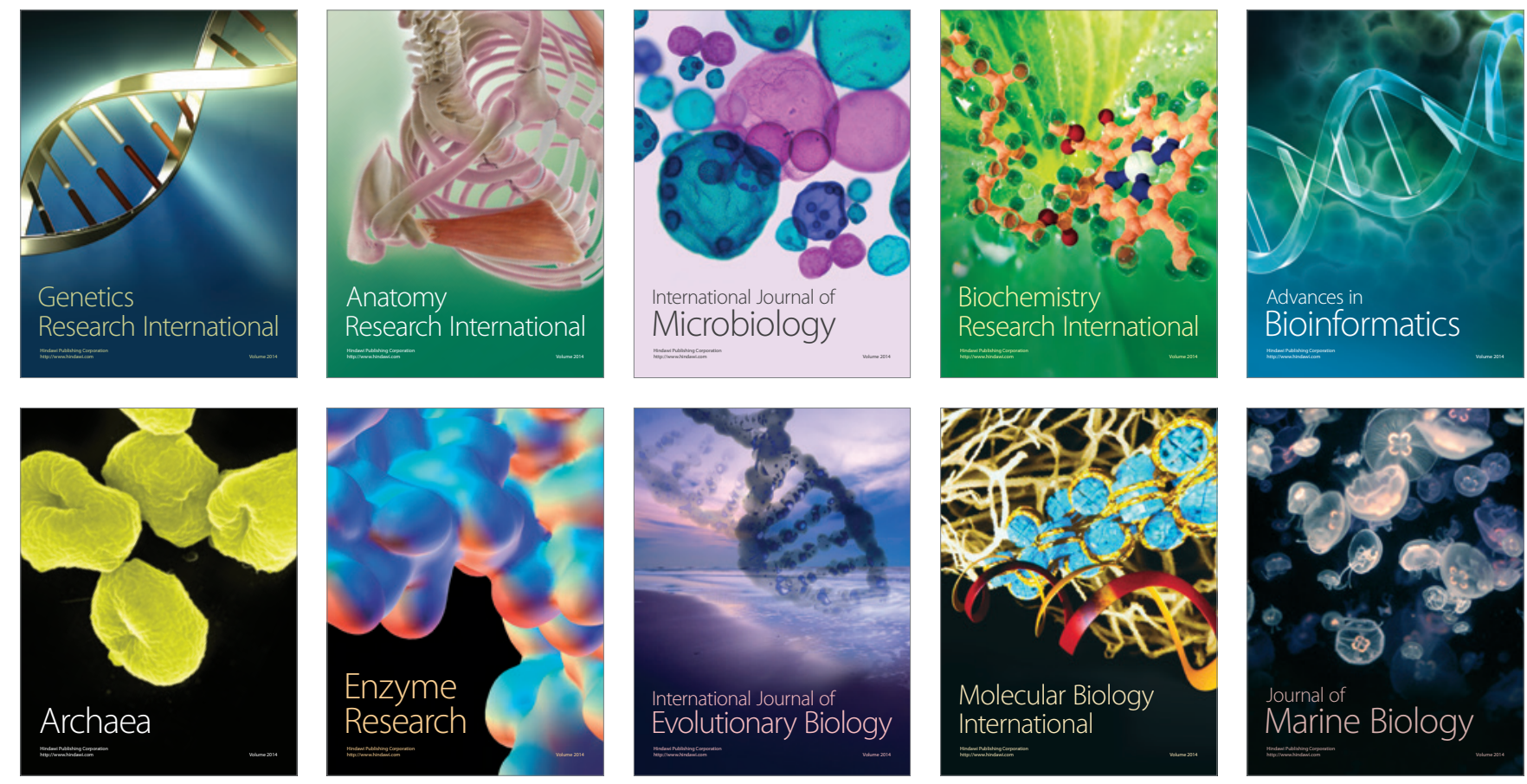